\title{
IDENTIFYING MANAGER'S ASPECTS ASSOCIATED WITH COMPANY'S INCOME THROUGH THE POINT-BISSERIAL CORRELATION: THE MIDDLE EUROPE EXAMPLE
}

\author{
Svitlana Bilan ${ }^{1, \mathrm{a}}$, David Melas ${ }^{2, \mathrm{~b},{ }^{*}}$ and Katarina Melasova ${ }^{3, \mathrm{c}}$ \\ ${ }^{1}$ Rzeszów University of Technology, al. Powstańców Warszawy 12, 35-959 Rzeszów, Poland \\ ${ }^{2}$ Faculty of Aeronautics, Technical University of Kosice, Rampova 7, 04121 Kosice, Slovakia \\ ${ }^{3}$ Faculty of Aeronautics, Technical University of Kosice, Rampova 7, 04121 Kosice, Slovakia \\ as.bilan@prz.edu.pl, ${ }^{\mathrm{b}}$ david.melas@gmail.com, ${ }^{\mathrm{c}}$ melasova@ gmail.com \\ *Corresponding author
}

Cite as: Bilan, S., Melas, D., Melasova, K. (2020). Identifying manager's aspects associated with company's income through the point-bisserial correlation: The middle Europe example. Ekonomickomanazerske spektrum, 14(1), 1-9.

Available at: dx.doi.org/10.26552/ems.2020.1.1-9

\begin{abstract}
For an existing company, it is necessary to generate a profit. In the beginning, there is an idea or thought that needs to be appropriately processed, and systems set up for everything to work. From the economic point of view, it is necessary to prove an individual capital, productive labour force, use of technologies, innovations. An efficient company operating on the middle Europe market is not the one meeting all requirements, but the one that can adequately manage all tasks and processes. In this research paper, we focused on aspects of the manager. We have created three groups that focus on knowledge, practice and personality of the manager. Subsequently, we created a database based on a questionnaire and examined these three groups as they are linked to the company's income through point-biserial correlation. The article begins with an Introduction, where we described the manager's aspects and how important they are for the managerial work. Subsequently, in the methodology, we described the basic principle of the point-biserial coefficient, which is the primary technique for identifying the relationships between aspects of the manager and income of the company. Unlike Pearson's coefficient, it measures the relationship between a dichotomous variable and a continuous. In the results, we identified the relationships between individual aspects and income and their significance.
\end{abstract}

Keywords: biserial correlation, manager, manager's role, key manager's aspects.

JEL Classification: C46, J53, M12

\section{Introduction}

The company needs enterprises, companies, factories, which employ its members - residents. However, not only society but also the companies themselves, organizations, and companies need to function inside. Every organization must have its management, its managers because they are the basis of its functioning. (Kerzner, 2017, Hassan et al., 2019)

Managers have a vital mission in every company because they influence their activities and results for better or worse. They strive to achieve the same goals and apply many procedures 
Identifying manager's aspects associated with company's income through the point-bisserial correlation:

The middle Europe example

Authors: Svitlana Bilan, David Melas and Katarina Melasova

for effective management at work. (Groysberg et al., 2018) Only the performance of managerial work, solving practical problems in contact with people and other organizations, as well as a critical reassessment of one's own opinions, attitudes, decisions, and actions, creates top managers and improves managerial functions in the company. (Guest, 2017, Welch et al., 2020).

Thanks to managers, companies function correctly, they are their mainstay. Therefore, we decided to describe the profession of the manager as a critical element of the company. The manager chooses to, he is responsible for the proper functioning of the company, he is liable for the company's profits, but he is also responsible for its loss. (Lopez-Fernandez et al., 2018, Brower and Dacin, 2020)

The individual managerial functions include firstly, planning and decision-making, secondly, organization, thirdly, people management and human resources, and fourthly, control. (Vidgen, 2017)

The manager must have specific skills, correct attitudes, and also appropriate character skills. Not every executive can be a manager, not everyone who wants to be a manager has the skills. (Kazaz, 2016; Golubov and Konstantinidi, 2019)

One of the factors that are important in managerial activity is knowledge. Every manager should have experience in the first place in the field of which the company is a part, not only be a kind of informant manager but should directly participate in the management and operation of the company based on their knowledge. (Bratianu et al., 2018; Jackson, 2020; Simsek, 2017)

Then there are practice and skills. It is prevalent that qualifications increase in proportion to the length of the traineeship. As essential skills are, the experience is necessary. (Taji and Bengo, 2019, Al Kazaz, 2016)

It is also imperative what character traits the manager has. It is impossible to develop a universal personality model and prove that a personality meeting the requirements of this model is guaranteed to achieve success in a particular management position (Sharma and Tarp, 2018; Morris, 2017). It is essential to be mentally balanced, stable, and emotionally mature. The manager gets into different situations every day, and it is up to him how he can deal with them, in what ways he establishes and maintains contacts, etc. (Varis et al., 2018; Ohiomah et al., 2019) Every manager should be thoroughly aware of his strengths but also his weaknesses. The attitudes of the manager are reflected in his behavior. Attitudes reflect scales of values that a person professes. (Al Taji and Bengo, 2019)

\section{Methodology}

Point biserial correlation is used to measure the direction and strength of the connection that exists between a dichotomous variable and a continuous variable. This is the Pearson correlation of product and moment, which applies when there are two continuous variables, while in this case one of the variables is measured on a dichotomous scale. Point biserial correlations are defined for designs with fixed or random group sample sizes and can accommodate unequal variations. Confidence intervals and standard errors for point biserial correlation estimates are derived from the sampling distributions for the common variant and the separate version of the standardized mean difference variant. (Bonett, 2019)

When mathematically expressing the biserial correlation coefficient, it is assumed that one of the samples is measured as dichotomous, and that the sample is actually normally distributed. In such cases, the point-biserial correlation generally underestimates the true value of the association. A better estimate in this case is provided by the biserial correlation coefficient. 
We assume that we have two sets $X=\{x 1, \ldots, x n\}$ and $Y=\{y 1, \ldots, y n\}$, where $x i$ are 0 or 1 , then the biserial correlation coefficient, denoted $r_{p b i}$, is calculated as follows (Brown, 2001, Habersang, 2019):

$$
r_{p b i}=\frac{\left.M_{p}-M_{q}\right)}{S_{t}} \sqrt{p q}
$$

where:

$r_{p b i}=$ point-biserial correlation coefficient,

$M_{p}=$ whole-test mean for students answering item correctly,

$M_{q}=$ whole-test mean for students answering item incorrectly,

$S_{t}=$ standard deviation for whole test,

$\mathrm{p}=$ proportion of students answering correctly,

$\mathrm{q}=$ proportion of students answering incorrectly.

Sheskin (2011) proposed the formula for the point-biserial correlation coefficient as:

$$
r_{b}=\frac{\left(\bar{Y}_{1}-\bar{Y}_{0}\right)}{S y} \sqrt{\frac{n p_{0}\left(1-p_{0}\right.}{n-1}}
$$

where:

$$
\begin{aligned}
& S_{Y}=\sqrt{\frac{\sum_{k=1}^{n}\left(Y_{k}-\bar{Y}\right)^{2}}{n-1}} \\
& \bar{Y}=\frac{\sum_{k=1}^{n} Y_{k}}{n} \\
& p_{1}=\frac{\sum_{k=1}^{n} X_{k}}{n} \\
& p_{0}=1-p_{1}
\end{aligned}
$$

The biserial correlation coefficient can also be computed from the point-biserial correlation coefficient using the following formula (Bonett, 2019):

$$
r_{b}=\frac{r_{p b} \sqrt{p_{0} p_{1}}}{y}
$$

\section{Results}

In the research paper, we dealt with three groups of factors mention above that are important for the manager. We decided to use Point-Biserial Correlation to reveal the relationships and their strength concerning the company's sales. For elaborating this study, companies were contacted, with revenues that they achieved for the previous calendar year 2019 in the range from 40 to 50 mil. Euros. We were able to reach 116 companies in total and were asked three questions, which answered yes/no. The questions concerned these three categories precisely and are dichotomized values. 
The implementation of the Point-Biserial Correlation is based on several assumptions. For example, one of the two variables is able to measure continuously. The next variable should be dichotomous. If another assumption is considered, there should be no deviations for the continuous variable.

Another critical assumption is that the continuous variable is normally distributed for each category of the dichotomous variable. We tested the normality using the Shapiro-Wilk normality test.

As part of the verification of normality, we set the following hypotheses:

HO: the sample has a normal distribution

H1: the sample does not have a normal distribution

We do not reject the null hypothesis of test normality at the significance level $\alpha=0.05$ according to results from the Table 1 .

Table 1: Test of Normality

Tests of Normality

\begin{tabular}{|c|c|c|c|c|c|c|}
\hline & \multicolumn{3}{|c|}{ Kolmogorov-Smirnov ${ }^{\mathrm{a}}$} & \multicolumn{3}{|c|}{ Shapiro-Wilk } \\
\hline & Statistic & $\mathrm{df}$ & Sig. & Statistic & $\mathrm{df}$ & Sig. \\
\hline output & .093 & 116 & .106 & .888 & 116 & .182 \\
\hline
\end{tabular}

a. Lilliefors Significance Correction

Source: Own Processing

If we consider the level alpha $=0.05$, then we reject the null hypothesis if the p-value is less than 0.05. In our case, according to the Shapiro-Wilk test, the value is 0.182 , in which circumstance we do not reject the null hypothesis, and the sample is normally distributed.

At the same time, for a continuous variable, there should be variations for each category of the dichotomous variable. We verify this using Levene's test of equality of variances.

Levene's null hypothesis is:

HO: The groups we compare have equal variance.

H1: The groups we compare do not have equal variance.

We accept the null hypothesis based on our verification in Table 2, and we have met the assumption.

Table 2: Test of Homogenity Variances

\begin{tabular}{cll|l}
\hline & & Levene Statistic & Sig. \\
\hline \multirow{2}{*}{ Based on Mean 1} & Based on Median & 7.295 & .000 \\
\cline { 2 - 4 } & Based on Median and with adjusted df & 1.221 & .006 \\
\cline { 2 - 4 } & Based on trimmed mean & 1.221 & .007 \\
\hline \multirow{2}{*}{ item 3 } & Based on Mean & 6.094 & .000 \\
\cline { 2 - 4 } & Based on Median & 4.254 & .000 \\
\hline & Based on Median and with adjusted df & .697 & .017 \\
\hline
\end{tabular}




\begin{tabular}{lll|l}
\hline \multicolumn{1}{c}{ Based on trimmed mean } & 3.572 & .000 \\
\hline \multirow{2}{*}{ item 4} & Based on Mean & 4.105 & .000 \\
\cline { 2 - 4 } & Based on Median & .664 & .025 \\
\cline { 2 - 4 } & Based on Median and with adjusted df & .664 & .028 \\
\cline { 2 - 4 } & Based on trimmed mean & 3.426 & .001 \\
\hline
\end{tabular}

Source: Own Processing

Based on the results from Table 3, it is possible to find out how the individual aspects of the manager correlate with the output or income of the company. The relationship between the output itself is perfectly correlated. When we move on to the next column, precisely item 1 , which represents the knowledge of the manager, we see that it is un-statistically significant. Pearson's correlation is positive (0.56), which means that answers marked "yes" correlate more with the output than response "no".

A similar scenario is repeated for item 2, which represents the experience and practice of the manager. Pearson's correlation is more significant than item 1, which means that more than "yes" answers are associated with the output.

In the case of item 3, which represents the personality of the manager and his approach is statistically significant and positive.

Table 3: Correlation between manager's aspects and income of the company

\begin{tabular}{|c|c|c|c|c|c|}
\hline \multicolumn{6}{|c|}{ Correlations } \\
\hline & & output & item 1 & item 2 & item 3 \\
\hline \multirow{3}{*}{ output } & Pearson Correlation & 1 & .056 & .141 & $.205^{*}$ \\
\hline & Sig. (2-tailed) & & .550 & .130 & .028 \\
\hline & $\mathrm{N}$ & 116 & 116 & 116 & 116 \\
\hline \multirow{3}{*}{ item 1} & Pearson Correlation & .056 & 1 & -.008 & -.060 \\
\hline & Sig. (2-tailed) & .550 & & .932 & .523 \\
\hline & $\mathrm{N}$ & 116 & 116 & 116 & 116 \\
\hline \multirow{3}{*}{ item 2} & Pearson Correlation & .141 & -.008 & 1 & $.851^{* *}$ \\
\hline & Sig. (2-tailed) & .130 & .932 & & .000 \\
\hline & $\mathrm{N}$ & 116 & 116 & 116 & 116 \\
\hline \multirow{3}{*}{ item 3} & Pearson Correlation & $.205^{*}$ & -.060 & $.851^{* *}$ & 1 \\
\hline & Sig. (2-tailed) & .028 & .523 & .000 & \\
\hline & $\mathrm{N}$ & 116 & 116 & 116 & 116 \\
\hline
\end{tabular}

*. Correlation is significant at the 0.05 level (2-tailed).

**. Correlation is significant at the 0.01 level (2-tailed).

Source: Own Processing

For better interpretation, we offer a graphical representation of the associations of managerial aspects with the income of the company.

Figure 1 shows the relationship between item 1 and output. We can see that the linear fit line is almost flat and indicates a slight increase; the slope is at the level of 0.51 . 
Identifying manager's aspects associated with company's income through the point-bisserial correlation: The middle Europe example Authors: Svitlana Bilan, David Melas and Katarina Melasova

Graph 1: Association between item 1 \& output



Source: Own processing

In Figure 2, the response score from 0 to 1 is a slightly increasing, and slope shows a level of 1.22 , which is more than in the previous case.

Figure 2: Association between item 2 \& output

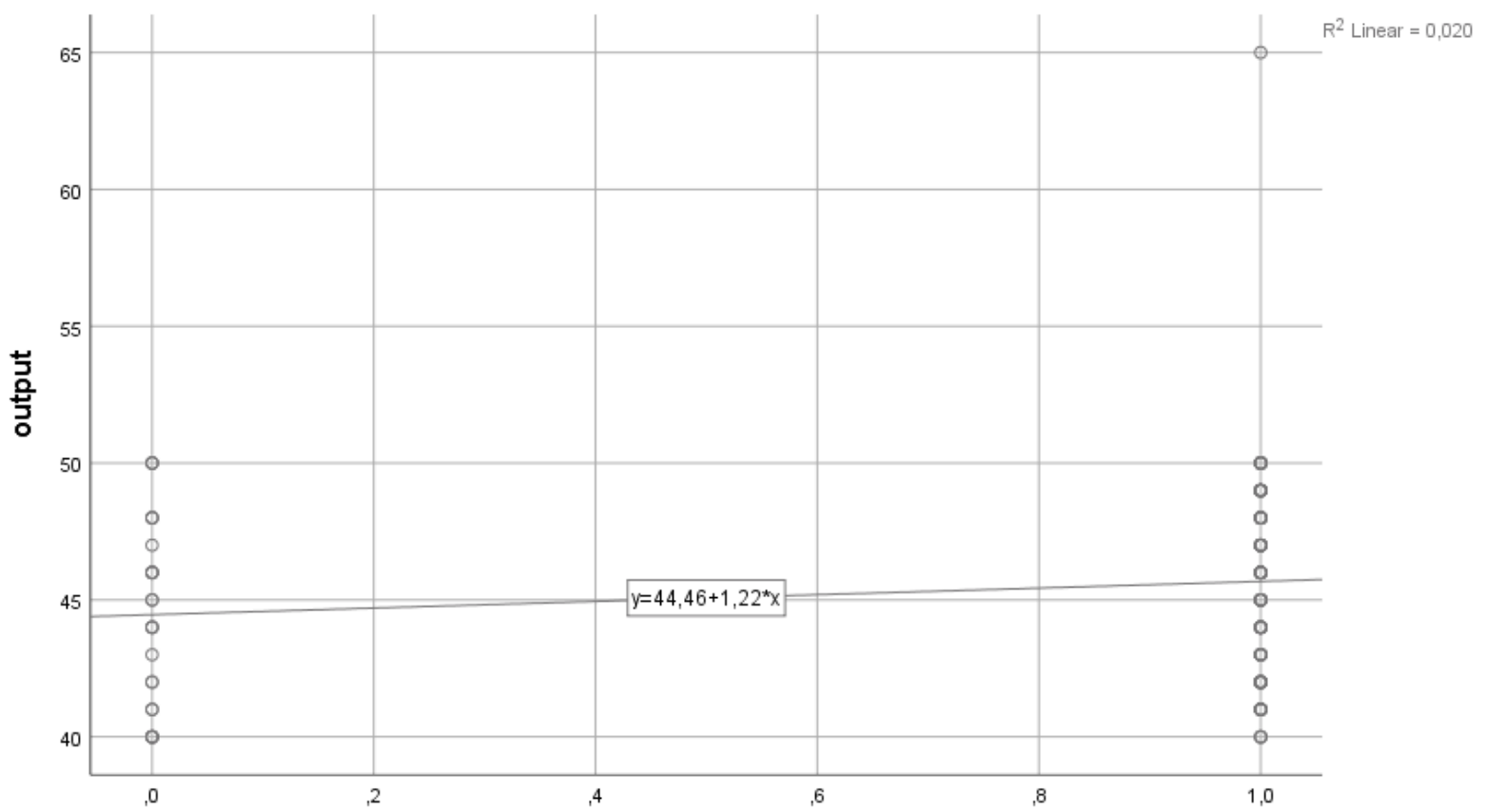

Source: Own processing

In the last case, the slope is the most pronounced and is equal to 1.76. The linear fit line has a growing character and is most noticeable in item 3 . 
Figure 3: Association between item 3 \& output

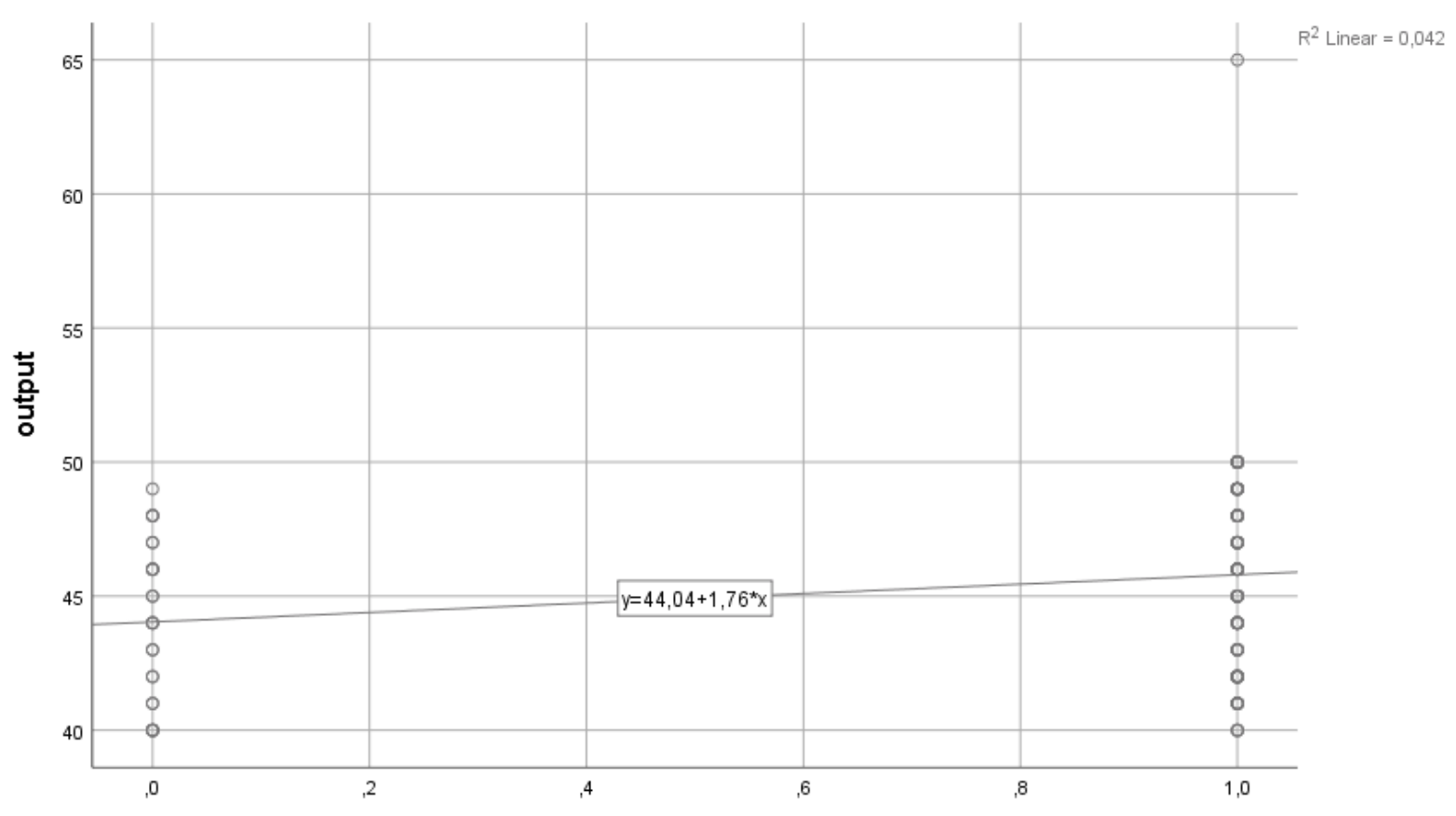

Source: Own processing

\section{Discussions}

Labor market conditions are very demanding on the personality of a person, a manager as well as on employees. In addition to vocational training, requirements such as the open expression of one's thoughts, appropriate communication with people, self-confidence, positive thinking, and the ability to assert oneself are also required. A manager with such skills can orientate himself in various crises, work, and interpersonal relationships. He is more confident, s/he can say what s/he feels; s/he decides for her/himself. Manager can accept criticism as well as other people's mistakes. "In actions and decisions, the manager can consider the possibilities and consequences of his works, for which he assumes responsibility. He is aware that he acts not only as an expert but also as a personality with the moral, will and character traits. He is expected to resolve the situation ethically. His performance will always be attributed to the ethical principle of the organization of which he is a part. Aligning morale with the economy is a very complex and complicated matter.

At the same time, each company has certain specifics, as well as the employees who work in it. There are several options and open questions that need to be addressed in further studies, like to the chosen technique.

For the needs of this study, we chose a point-biserial coefficient. In the future, it would be good to examine the interrelationships by another method and then compare the results of the analyzes. At the same time, this technique is used for a smaller number of companies, usually up to 50, some studies claim that a sample of up to 1000 is suitable, but in the eventuality, it would be necessary to consider this alternative and then compare the results.

\section{Conclusion}

The profession of manager, and especially the manager, requires excellent professionalism, mental and physical fitness, moral and ethical credit. Every organization strives to increase the 
Identifying manager's aspects associated with company's income through the point-bisserial correlation:

The middle Europe example

Authors: Svitlana Bilan, David Melas and Katarina Melasova

work performance of its employees and achieve good economic results. He fills the positions of managers with people who support their co-workers, communicates with them and motivates them to achieve their goals. The art of being a leader lies in the ability to stimulate and motivate employees to work creatively, with mutual trust, respect, esteem, and responsibility playing a pivotal role here. If a manager wants to be a real professional, he needs to work on himself, because only strong personalities can compete. Self-motivation can develop a character that brings inner fulfilment, recognition and joy to the manager in the leadership position. By being able to create the right conditions for him, the manager is more motivated and pursues better performance, because success and recognition are the most motivating. In our study, we analyzed the profile of the manager, specific aspects: knowledge, experience and personality. Based on the results of the analysis, we concluded that the most considerable influence on the income of the company has the nature of the manager. The style in which he can work with employees to motivate them and increase their productivity and at the same time, the ability to establish new contacts and win new orders. It is not enough for a company to have the latest technologies, the best experts, to monitor innovations, but to have the right managers, which can be a competitive advantage for the company.

\section{References}

Al Kazaz, M. (2016). The impact of managers' leadership skills on construction project performance in Dubai. International Journal of Managerial Studies and Research (IJMSR), 4(6), pp. 73-94.

Al Taji, F. N. A. and Bengo, I. (2019). The distinctive managerial challenges of hybrid organizations: which skills are required? Journal of Social Entrepreneurship, 10(3), pp. 328-345.

Bonett, D.G. (2019). Point-biserial correlation: Interval estimation, hypothesis testing, meta-analysis, and sample size determination. British Journal of Mathematical and Statistical Psychology.

Bratianu, C., Vatamanescu, E. M. and Anagnoste, S. (2018). The influence of knowledge dynamics on managerial decision-making process. Proceedings of the 19th European Conference on Knowledge Management, pp. 104111.

Brower, J. and Dacin, P. A. (2020). An institutional theory approach to the evolution of the corporate social performance - corporate financial performance relationship. Journal of management studies, 57(4), pp. 805836.

Brown, J. D. (2001). Point-biserial correlation coefficients. Statistics, 5(3).

Golubov, A. and Konstantinidi, T. (2019). Where is the risk in value? Evidence from a Market-to-Book decomposition. Journal of Finance, 74(6), pp. 3135-3186.

Groysberg, B., Lee, J., Price, J. and Cheng, J. (2018). The leader's guide to corporate culture. Harvard Business Review, 96(1), pp. 44-52.

Guest, D. E. (2017). Human resource management and employee well-being: Towards a new analytic framework. Human Resource Management Journal, 27(1), pp. 22-38.

Hassan, T. A., Hollander, S., van Lent, L. et al. (2019). Firm-level political risk: Measurement and effects. Quarterly Journal of Economics, 134(4), pp. 2135-2202.

Habersang, S., Kueberling-Jost, J., Reihlen, M. et al. (2019). A process perspective on organizational failure: A qualitative meta-analysis. Journal of Management Studies, 56(1), pp. 19-56.

Jackson, T., Shen, J., Nikolic, S. and Xia, G. (2020). Managerial factors that influence the success of knowledge management systems: A systematic literature review. Knowledge and Process Management, 27(2), pp. 77-92.

Kerzner, H. (2017). Project management: a systems approach to planning, scheduling, and controlling. John Wiley \& Sons.

Lopez-Fernandez, M., Romero-Fernandez, P. M. and Aust, I. (2018). Socially responsible human resource management and employee perception: the influence of manager and line managers. Sustainability, 10(12), pp. 4614.

Morris, M. (2017). Managerial agency: Personality, psychopathy, structure and leadership. (Doctoral dissertation, Keele University).

Ohiomah, A., Andreev, P., Benyoucef, M. and Hood, D. (2019). The role of lead management systems in inside sales performance. Journal of Business Research, 102, pp. 163-177.

Simsek, H. (2017). Considerations of managerial change in knowledge based organization. Valahian Journal of Economic Studies, 8(4). 
Sheskin, D. J. (2011). Handbook of parametric and nonparametricstatistical procedures, (5th ed). Boca Raton, FL: Chapman \&Hall/CRC.

Sharma, S. and Tarp, F. (2018). Does managerial personality matter? Evidence from firms in Vietnam. Journal of Economic Behavior \& Organization, 150, pp. 432-445.

Varis, K., Majaniemi, N. and Wilderom, C. P. (2018). Recruiting happy, socio-emotionally balanced and mature managers in Finland and elsewhere. Organization 4.1: The role of values in the organizations of the 21st century, pp. 342.

Vidgen, R., Shaw, S. and Grant, D. B. (2017). Management challenges in creating value from business analytics. European Journal of Operational Research, 261(2), pp. 626-639.

Welch, X., Pavicevic, S., Keil, T. et al. (2020). The pre-deal phase of mergers and acquisitions: A review and research agenda. Journal of Management, 46(6), pp. 843-878. 